\title{
Seasonal Prediction of Winter Precipitation Anomalies over Central Southwest Asia: A Canonical Correlation Analysis Approach
}

\author{
SAPNA RANA, JAMES RENWICK, AND JAMES MCGREGOR \\ School of Geography, Environment and Earth Sciences, Victoria University of Wellington, Wellington, \\ New Zealand \\ ANKITA SINGH \\ School of Earth, Ocean and Climate Sciences, Indian Institute of Technology, Bhubaneswar, India
}

(Manuscript received 27 February 2017, in final form 10 October 2017)

\begin{abstract}
Central southwest Asia $\left(\mathrm{CSWA} ; 20^{\circ}-47^{\circ} \mathrm{N}, 40^{\circ}-85^{\circ} \mathrm{E}\right)$ is a water-stressed region prone to significant variations in precipitation during its winter precipitation season of November-April. Wintertime precipitation is crucial for regional water resources, agriculture, and livelihood; however, in recent years droughts have been a notable feature of CSWA interannual variability. Here, the predictability of CSWA wintertime precipitation is explored based on its time-lagged relationship with the preceding months' (September-October) sea surface temperature (SST), using a canonical correlation analysis (CCA) approach. For both periods, results indicate that for CSWA much of the seasonal predictability arises from SST variations in the Pacific related to El Niño-Southern Oscillation (ENSO) and the Pacific decadal oscillation (PDO). Additional sources of skill that play a weaker predictive role include long-term SST trends, North Atlantic variability, and regional teleconnections. CCA cross-validation skill shows that the regional potential predictability has a strong dependency on the ENSO phenomenon, and the strengthening (weakening) of this relationship yields forecasts with higher (lower) predictive skill. This finding is validated by the mean cross-validated correlation skill of 0.71 and 0.38 obtained for the 1980/81-2014/15 and 1950/51-2014/15 CCA analyses, respectively. The development of cold (warm) ENSO conditions during September-October, in combination with cold (warm) PDO conditions, is associated with a northward (southward) shift of the jet stream and a strong tendency of negative (positive) winter precipitation anomalies; other sources of predictability influence the regional precipitation directly during non-ENSO years or by modulating the impact of ENSO teleconnection based on their relative strengths.
\end{abstract}

\section{Introduction}

Central southwest Asia (CSWA), bounded by the domain $20^{\circ}-47^{\circ} \mathrm{N}, 40^{\circ}-85^{\circ} \mathrm{E}$ (Fig. 1 ), comprises a region that is water-stressed and societally vulnerable (Barlow and Tippett 2008). Characterized by semiarid to arid climate, the complex topography of CSWA plays a dominant role in the seasonal and regional distribution of precipitation (Rana et al. 2017). A large part of the region lies beyond the usual reach of the Indian summer monsoon [e.g., Fig. 2 in Rana et al. (2015)] and receives most of its annual precipitation during winter and early spring season [November-April (NDJFMA); see Fig. 2c herein] associated with eastward-propagating

Corresponding author: Sapna Rana, sapna.rana@vuw.ac.nz midlatitude cyclones (Martyn 1992). The winter precipitation, which mostly falls as snow over the mountain ranges and as rainfall in submountainous and lowelevation plains, is of major importance for local water resources, agriculture production, industrial needs, and livelihood.

CSWA winter precipitation displays considerable interannual variability (Fig. 2a) with frequent and notable droughts (Mariotti 2007; Barlow et al. 2016). For example, CSWA has experienced two catastrophic droughts in 1999-2001 (Barlow et al. 2002, 2016) and 2007/08 (Trigo et al. 2010; Hoell et al. 2012) that adversely affected the region's water supplies, crops, food supplies, livestock, and quality of life, and further resulted in large population migration and political instability (Agrawala et al. 2001; Gall 2008). Evidence 


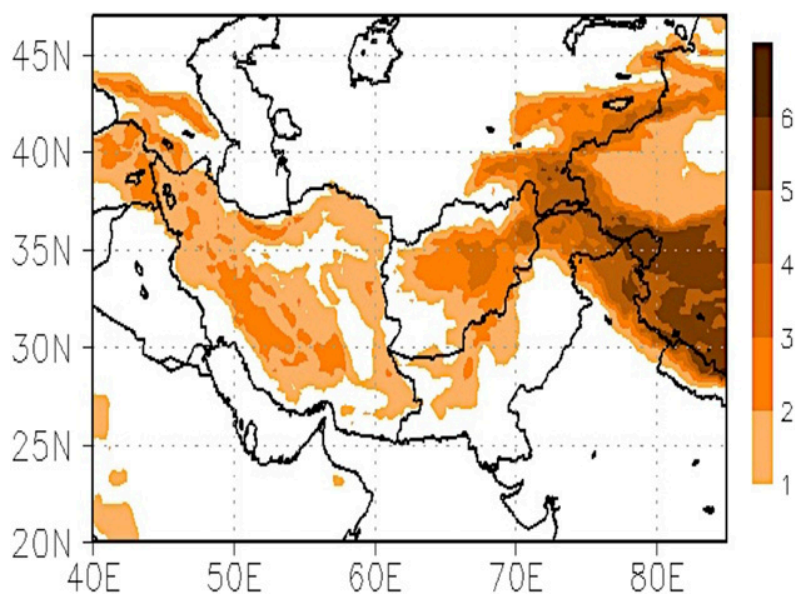

FIG. 1. Topography $(\mathrm{km})$ of CSWA $\left(20^{\circ}-47^{\circ} \mathrm{N}, 40^{\circ}-85^{\circ} \mathrm{E}\right)$.

indicates that prolonged periods of suppressed winter precipitation over CSWA are related to negative sea surface temperature (SST) anomalies in the central, eastern tropical, and eastern extratropical Pacific in combination with positive SST anomalies in the warm tropical and extratropical western Pacific Ocean (Barlow et al. 2002; Hoerling and Kumar 2003; Hoell et al. 2015a). The physical mechanism connecting the western Pacific convection and SST anomalies with CSWA precipitation is through modification of the regional circulation by means of exciting baroclinic
(Barlow et al. 2002, 2005; Hoell et al. 2012) and barotropic (Hoell et al. 2013) stationary Rossby waves over CSWA.

Links between CSWA winter precipitation and Maritime Continent convection have also been explored. An observational study by Lau and Boyle (1987) showed that the extratropical circulation is more sensitive to convection and heating over the Maritime Continent than to convection over the central Pacific. It has been noted that enhanced Maritime Continent convection leads to upper-level divergence and a southerly flow into the subtropical Northern Hemisphere (Tippett et al. 2003), resulting in strong anticyclonic circulations over the CSWA region (Liebmann 1987). Recently, Barlow et al. (2005) and Hoell et al. (2012, 2015a) reported that enhanced (reduced) convection over the eastern Indian Ocean and Maritime Continent excites warm (cold) core anticyclones (cyclones) over southwest Asia, resulting in suppressed (enhanced) wintertime precipitation over the CSWA region.

The above findings provide strong evidence that CSWA precipitation is strongly linked to tropical Pacific forcing, with circulation anomalies influencing the regional precipitation through changes in moisture transport (Barlow et al. 2002; Mariotti 2007; Barlow and Tippett 2008; Hoell and Funk 2013; Kar and Rana 2014). These linkages suggest the possibility of potential predictability over CSWA and can form an important basis

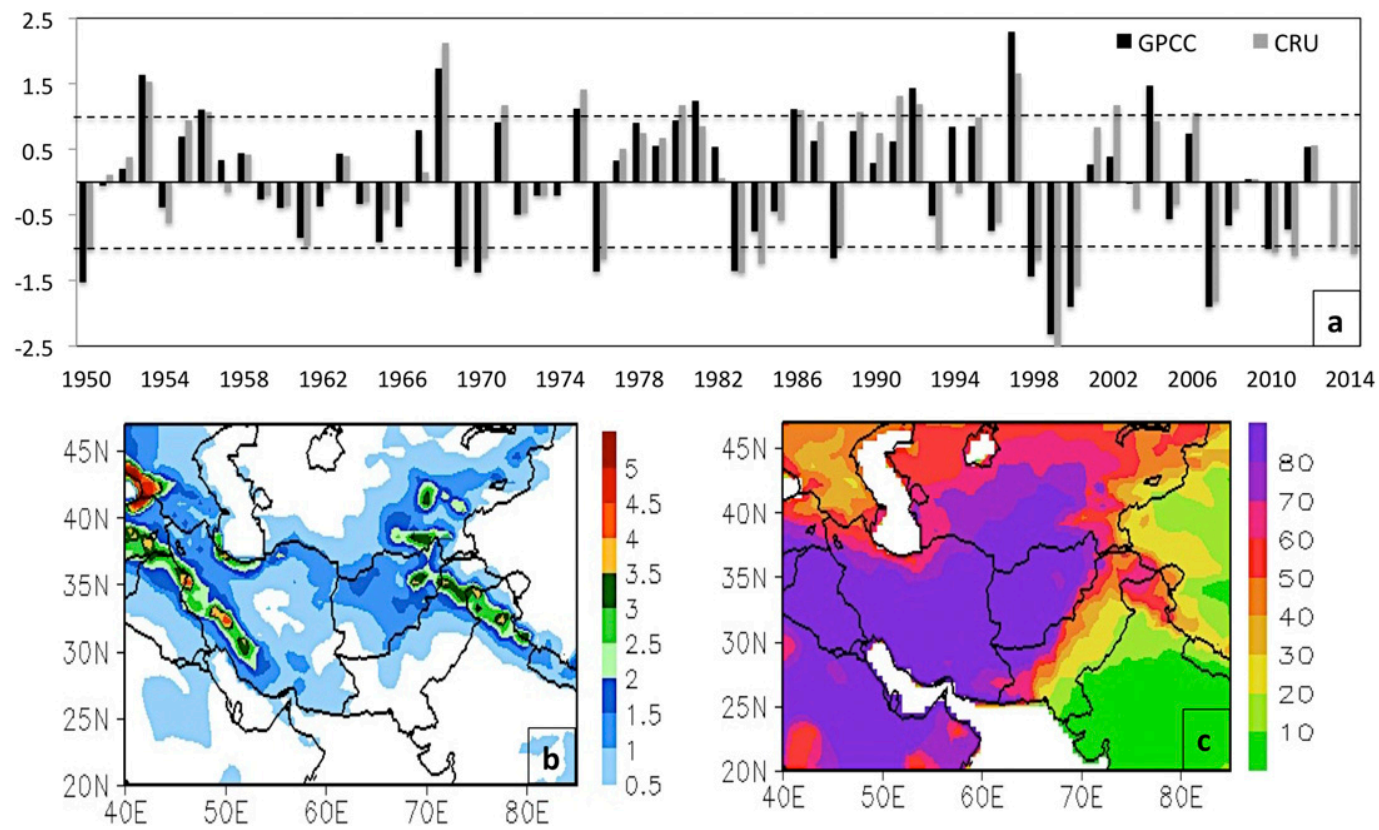

FIG. 2. (a) Area-averaged winter season (NDJFMA) standardized precipitation anomaly, (b) spatial distribution of winter season precipitation $\left(\mathrm{mm} \mathrm{day}^{-1}\right)$, and (c) percentage contribution of NDJFMA precipitation to the total annual precipitation over CSWA for 1950/51-2014/15. 
for predicting seasonal climate anomalies over the region at both intraseasonal and interannual time scales (Tippett et al. 2003, 2005; Barlow et al. 2005, 2016). Nonetheless, very few assessments have been reported that explore the predictability of the observed seasonal precipitation anomalies over CSWA using these relationships.

The objective of this study is to determine whether the above-discussed linkages are statistically robust enough to provide skillful seasonal prediction of CSWA wintertime precipitation anomalies via timelagged relationships between the regional wintertime (NDJFMA) precipitation and the SST variability in the preceding months (September-October). To explore this, we develop a statistical prediction model based on the canonical correlation analysis (CCA) approach.

CCA is a multivariate statistical technique that has been widely used in atmospheric sciences, mostly for the purpose of identifying linearly related patterns of variability between two datasets (predictors and predictands) by maximizing the temporal correlation between them (Barnett and Preisendorfer 1987; Bretherton et al. 1992; Barnston and Smith 1996; Yu et al. 1997; Tippett et al. 2008). The reason for considering CCA over other statistical techniques is its ability to operate on full fields and to objectively define the most highly related patterns of predictor and predictand (Barnett and Preisendorfer 1987). Moreover, CCA gives an extensive set of diagnostics that offer useful insights into the physical basis of the relationships used to form the predictions (Barnston et al. 1996).

The outline of the paper is arranged as follows. In section 2, we present the datasets. Section 3 briefly discusses the methods of analysis, including the CCA statistical technique. The choice of potential predictor and CCA prediction results are discussed in section 4, followed by the large-scale teleconnection dynamics in section 5. Finally, section 6 summarizes our major findings.

\section{Datasets}

\section{a. Observed precipitation}

Monthly gridded observational precipitation data are obtained from the Global Precipitation Climatology Centre (GPCC) full data reanalysis version 7 (Schneider et al. 2014). The data are available from http://gpcc.dwd.de for the period $1901-2013$ at $0.5^{\circ}, 1.0^{\circ}$, and $2.5^{\circ}$ latitudelongitude resolutions. The current analysis uses $0.5^{\circ}$ data from 1950 to 2013. In addition to the GPCC data, the Climatic Research Unit (CRU) time series (TS) version 3.24.01 monthly gridded precipitation records are available from https://crudata.uea.ac.uk/cru/data/. The dataset covers the period $1901-2015$ at a $0.5^{\circ}$ resolution (Harris et al. 2014). Here data from 1950 to 2015 are used.

Figure 2a shows the CSWA winter season (NDJFMA) precipitation time series calculated as the area average of standardized precipitation anomalies from each of the GPCC (1950/51-2012/13) and CRU (1950/51-2014/15) datasets. Because of the sparseness of ground-based measurements in CSWA, the accuracy of gridded precipitation datasets is limited over much of this region (Barlow and Tippett 2008; Rana et al. 2015). However, a recent analysis by Rana et al. (2017) showed that in this region GPCC precipitation estimates are more realistic and reliable compared to some of the currently available observational datasets including CRU. Therefore, for our analysis GPCC precipitation records are used from 1950 up to 2013 and CRU data thereafter. The spatial maps of the CSWA wintertime precipitation climatology and its seasonal percentage contribution to the total annual precipitation for the analysis period (1950/51-2014/15) are shown in Figs. 2b and 2c, respectively. More details, including CSWA winter precipitation regimes and performance assessment of various available gridded precipitation datasets (observations, reanalysis, and satellite-derived data), can be found in Rana et al. (2017).

\section{b. SST data}

The global monthly observed SST $\left({ }^{\circ} \mathrm{C}\right)$ data were obtained from the Extended Reconstructed Sea Surface Temperature (ERSST) analysis version 5 (Huang et al. 2017). This dataset is produced on a fixed $2^{\circ}$ latitudelongitude resolution, available from https://www.esrl. noaa.gov/psd/data/gridded/data.noaa.ersst.v5.html for the period 1854 to the present.

\section{c. Reanalysis winds}

Monthly zonal and meridional components of winds $\left(\mathrm{m} \mathrm{s}^{-1}\right)$ at 300,500 , and $850 \mathrm{hPa}$ were taken from the European Centre for Medium-Range Weather Forecasts (ECMWF) interim reanalysis (ERA-Interim; http:// rda.ucar.edu/datasets/ds627.0/). The ERA-Interim data are available from 1979 to the present, at 37 atmospheric levels and different horizontal resolutions $\left(0.25^{\circ}, 0.75^{\circ}\right.$, and $1.5^{\circ}$ ) for the entire globe (Dee et al. 2011). Here we use $0.75^{\circ}$ wind field data.

\section{Method of analysis}

The relationship between CSWA year-to-year wintertime (NDJFMA) precipitation variations and the global precursor field [mean SST (September-October)] is examined using covariance analysis. Note that the lagged relationship signal between CSWA winter precipitation 
and September-October mean SSTs was slightly stronger in comparison to that with August-October mean SSTs. Statistical significance of the computed covariance matrix is assessed at each grid point using the $F$ statistics at $5 \%$ significance level. The spatial covariance map helps to isolate the dominant predictive signatures that are important for CSWA precipitation variations, and can potentially be used in the construction of the CCA prediction scheme.

CCA is a multivariate statistical technique that computes linear combinations of a set of predictors that maximizes relationships, in the least squares sense, to the similarly calculated linear combinations of a set of predictands (Barnston and Ropelewski 1992). In the simplest sense, the aim of CCA is to find the most highly correlated patterns between the predictor and predictand fields. The linear combinations are called canonical variates, and the correlation between the pairs of canonical variates is referred to as the canonical correlation. More details on CCA can be found in Barnett and Preisendorfer (1987), Yu et al. (1997), and Marzban et al. (2014). Extensive treatment of the mathematical basis of CCA is provided in Graham et al. (1987).

In this study, CCA experiments are performed for two sets of time periods, 1950/51-2014/15 (65 yr) and 1980/81-2014/15 (35 yr), using the SST anomaly as the predictor dataset and the CSWA wintertime precipitation anomaly as the predictand. The choice of SST as a predictor is based on the rationale that the slow timescale response of the oceans constitutes an important source of predictability at various time scales ranging from seasonal to interannual (Barnston and Smith 1996). Prior to conducting CCA, the predictor and the predictand matrices are standardized and orthogonalized using standard EOF analysis. The EOF analysis reduces the large dimensionality of the original data matrices by retaining a limited number of EOF modes, and helps to avoid overfitting. In addition, incoherent variability (noise) is also filtered out since EOF analysis focuses mostly on the dominant patterns of variability within each input dataset. As there is no universally agreed procedure for determining how many EOF modes should be retained (Yu et al. 1997), the number retained here is such that the maximum variance explained by the chosen number of modes is $85 \%$ for the predictor and $75 \%$ for predictand. Based on this, the leading 22 (15) EOFs of the predictor and 21 (13) EOFs of the predictand matrices are used for the period 1950/51-2014/15 (1980/81-2014/15), respectively. The EOF time components are cross-correlated and the resulting cross-correlation matrix is diagonalized to determine the maximal (canonical) correlations and associated canonical variates. Further, a simple linear regression model is constructed that relates the predictand canonical variates to the predictor canonical variates (Wilks 1995) and forecast skill assessment is undertaken using the leave-one-out cross-validation approach, wherein each year in the time series is held out in turn and the remaining years are used for developing the CCA model.

Detailed model validation is carried out for the 1980/812014/15 prediction experiment, for which dry (negative precipitation anomalies) and wet (positive precipitation anomalies) years are identified in the area-averaged time series using the bottom and top 20 percentiles, respectively. The seven driest years (1983/84, 1988/89, 1998/ 99, 1999/2000, 2000/01, 2007/08, and 2010/11) and seven wettest winter precipitation years $(1980 / 81,1981 / 82$, 1986/87, 1992/93, 1995/96, 1997/98, and 2004/05) are selected. Three verification statistics-1) mean bias, 2) root-mean-square error (RMSE), and 3) temporal anomaly correlation between forecast and observed precipitation anomalies-are computed, and the model predictive skill is evaluated for out-of-sample prediction against a null/climatology model (mean rainfall) and memory/persistence model (last year's rainfall as this year's prediction). For a better understanding of the dynamic precursors that lead to wintertime precipitation variations over CSWA, concomitant seasonal mean circulation anomalies are examined at different levels (300, 500 , and $850 \mathrm{hPa}$ ) for the aforementioned dry and wet year composites.

\section{Results}

\section{a. Potential predictor}

To explore the seasonal lead-lag relationships between September-October SST variability and CSWA winter (NDJFMA) precipitation, a spatial covariance map is generated to isolate the large-scale coupled patterns of linear variability between the two variables. Previous work has identified that one of the most dominant perturbations responsible for CSWA interannual precipitation variations is related to ENSO (Barlow et al. 2002; Mariotti 2007; Hoell et al. 2014a,b, 2017). However, other modes of variability such as the North Atlantic Oscillation (NAO) (Cullen et al. 2002; Filippi et al. 2014; Kar and Rana 2014), the east Atlantic-western Russia (EAWR) pattern (Yin et al. 2014; Krichak et al. 2014), the Madden-Julian oscillation (MJO) (Barlow et al. 2005; Hoell et al. 2012), Pacific decadal variability (PDV), and long-term change in global sea surface temperatures (Hoell et al. 2015b) have also been linked to CSWA precipitation variations at various time scales. 


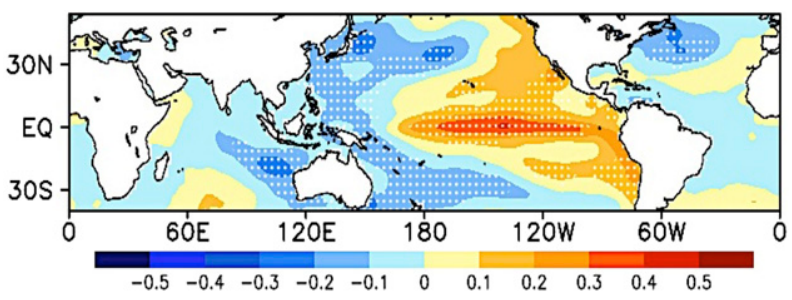

FIG. 3. Covariance map between CSWA winter precipitation $\left(\mathrm{mm} \mathrm{day}^{-1}\right)$ and the preceding months' (September-October) mean SST $\left({ }^{\circ} \mathrm{C}\right)$ for $1950 / 51-2014 / 15$. White stippling indicates covariance significant at $5 \%$ level ( $F$ statistics).

In Fig. 3 the lagged covariability pattern between CSWA precipitation and SSTs between $35^{\circ} \mathrm{S}$ and $50^{\circ} \mathrm{N}$ strongly resembles the El Niño-Southern Oscillation (ENSO) pattern (Deser et al. 2010; Johnson 2013). The spatial pattern reveals that enhanced (reduced) wintertime precipitation anomalies over CSWA are related to a warm (cold) central, eastern tropical, and eastern extratropical Pacific Ocean in co-occurrence with cold (warm) western tropical and western extratropical $\mathrm{Pa}$ cific Ocean. The large-amplitude pattern of zonally strong positive SST anomalies across two-thirds of the equatorial Pacific Ocean, flanked by relatively strong negative anomalies in the western Pacific and eastern Indian Ocean, reinforces the finding that ENSO-related Pacific SST forcing is one of the primary causes of CSWA wintertime precipitation variations (Barnston and Smith 1996; Hoerling and Kumar 2003; Hoell et al. 2014a).

The distribution of weaker positive SST anomalies on the eastern side of the tropical Atlantic Ocean along with statistically significant negative SST anomalies southeast of Newfoundland is characteristic of an NAO pattern (Cassou et al. 2004; Czaja and Frankignoul 2002). This result shows that the negative (positive) phase of the NAO is responsible for increased (reduced) winter precipitation activity over CSWA. Evidence also suggests that the positive (negative) NAO phase is associated with more meridional (zonal) surface winds and storm tracks in the North Atlantic sector, resulting in cool/dry (warm/ wet) winters in the Mediterranean region and into the Middle East (Cullen and deMenocal 2000; Aizen et al. 2001).

Based on the above, we infer that CSWA winter precipitation is influenced by both the ENSO-related SST forcing and the Atlantic Ocean variability modulated by the NAO. However, in a recent study Hoell et al. (2017) noted that the long-term (1901-2012) relationship between wintertime ENSO and CSWA precipitation has varied in strength throughout time. To explore this, in Fig. 4 we compute the 17-yr sliding correlation between CSWA winter precipitation and the preceding months' (September-October) Niño-3.4 and NAO index (available at https://www.esrl.noaa.gov/psd/ gcos_wgsp/Timeseries/). As illustrated by the temporal fluctuations in Fig. 4, the Niño-3.4 (NAO) influence on CSWA precipitation strengthened to (weakened from) a statistically significant level around the early 1980s and continued to increase (decrease) thereafter. Given the notable change in the relationships among CSWA precipitation, Niño-3.4, and the NAO, two separate time periods, $1950 / 51-2014 / 15$ (65 yr) and 1980/81$2014 / 15$ ( $35 \mathrm{yr}$ ), are considered to test the robustness of the CCA prediction approach adopted here.

CCA-based forecasts are typically sensitive to the choice and size of the predictor domain (RecaldeCoronel et al. 2014); therefore, to determine the most optimal model CCA experiments were performed with different possible predictors [outgoing longwave radiation (OLR), upper-level winds, and SST] and combinations of predictor domains that included the Indo-Pacific, Pacific, and the Atlantic Ocean domains. The highest overall skill (domain average) was achieved

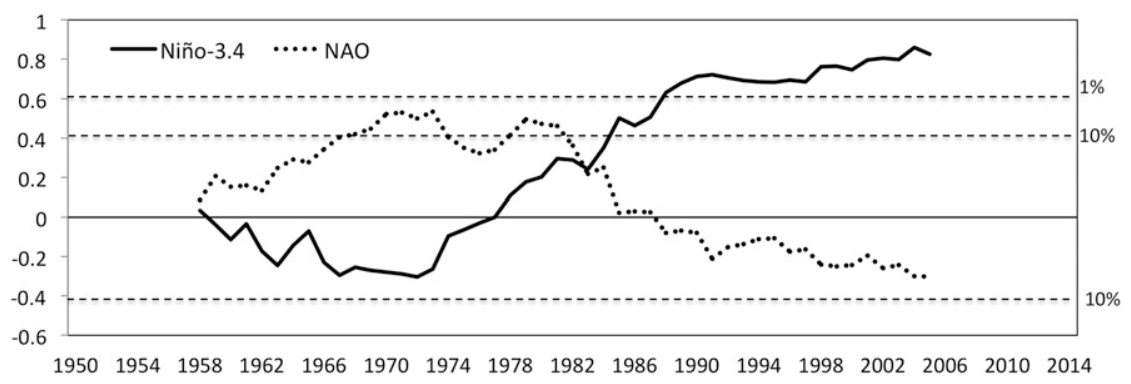

FIG. 4. Sliding correlation between CSWA winter precipitation anomalies and the September-October Niño-3.4 (solid line) and the NAO (dotted line) index on 17-yr window. Values are plotted at the center of each 17 -yr period and statistical significance at $10 \%$ and $1 \%$ confidence level is achieved by the two-tailed Student's $t$ test for correlations greater than 0.41 and 0.61 , respectively, indicated by horizontal dashed lines. 

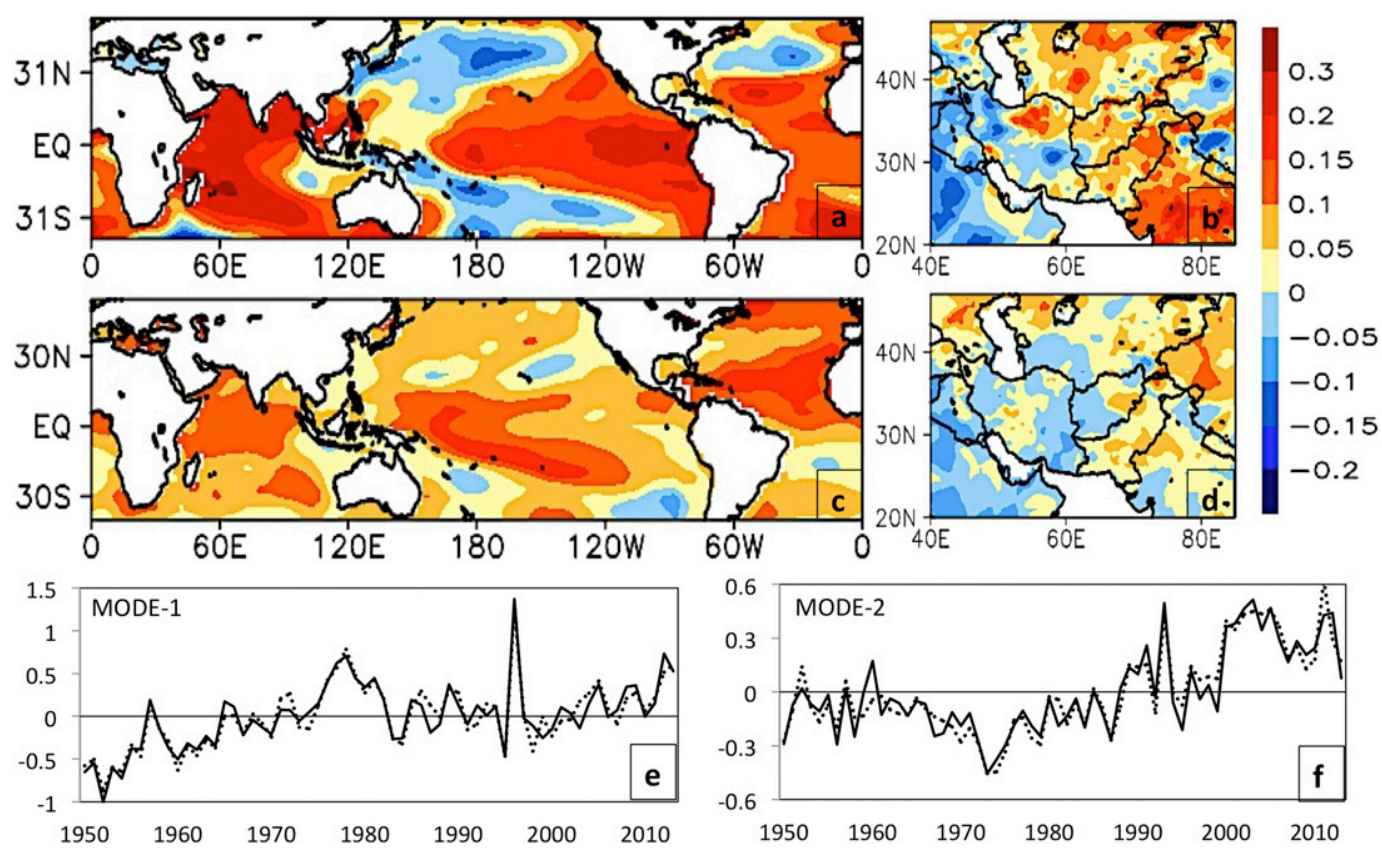

FIG. 5. The predictor (September-October SSTs) and predictand (NDJFMA CSWA precipitation) loading patterns for the CCA (a),(b) mode 1 and (c),(d) mode 2 and the corresponding canonical component normalized time series (SST, dotted line, and precipitation, solid line) for the period 1950/51-2014/15.

for the quasi-global $\left(40^{\circ} \mathrm{S}-55^{\circ} \mathrm{N}\right.$, all longitudes) SSTpredictor domain that we use as input in the CCA model predictions described below.

As mentioned previously, the CCA technique finds canonical variate pairs with the highest possible Pearson's correlation coefficient. The respective canonical variate values, known as loadings, measure the contribution of the corresponding original variable to the transformed canonical variate (Marzban et al. 2014). Examination of these loadings often helps in deriving a meaningful interpretation of the physical processes related to that canonical variate pair. In the following section, we interpret the physical meaning of the loading patterns and the corresponding amplitude time series generated for the leading two modes of maximally correlated canonical variate pairs in our predictor and the predictand matrices.

\section{b. CCA maps}

The spatial predictor-predictand loadings for the first two CCA modes and the associated canonical component time series for the period 1950/51-2014/15 and 1980/81-2014/15 are displayed in Figs. 5 and 6, respectively. Previous work has identified that the main sources of predictability on the seasonal and interannual time scales come from the long-term trends in SSTs and the ENSO (Barnston and Smith 1996; Goddard et al. 2001). Here, the first predictor mode (Fig. 5a) for the period 1950/51-2014/15 explains 27\% of the domain variance and exhibits broad positive SST loadings over the tropical Pacific and along the west coast of North America accompanied by negative SST anomalies in the central and western North Pacific. The spatial structure resembles the ENSO-like decadal variability of Zhang et al. (1997), a global signature of the Pacific decadal oscillation (PDO) described in Newman et al. (2016). This mode also features a distinct warming of the southern oceans as indicated by the like-signed positive SST anomalies mainly south of the equator and negative SSTs in the central North Pacific and the North Atlantic. A similar SST warming trend has been reported in Shabbar et al. (2011) and Smith and Reynolds (2003).

The leading predictand loading pattern of CSWA winter precipitation (Fig. 5b) accounts for $19 \%$ of the total domain variance and is characterized by a westeast precipitation dipole pattern. Given the anomalous temperature gradient of the tropical and the Northern Hemisphere midlatitude SSTs seen in Fig. 5a, the westeast precipitation loadings could possibly be related to the shift in the mean structure and flow (troughs and ridges) of the Rossby waves associated with the subtropical jet stream over CSWA. The corresponding canonical component time series associated with CCA mode 1 (Fig. 5e) have a high correlation coefficient of 0.95 . The time series indicate a moderate amount of year-to-year variability superimposed by the influence 


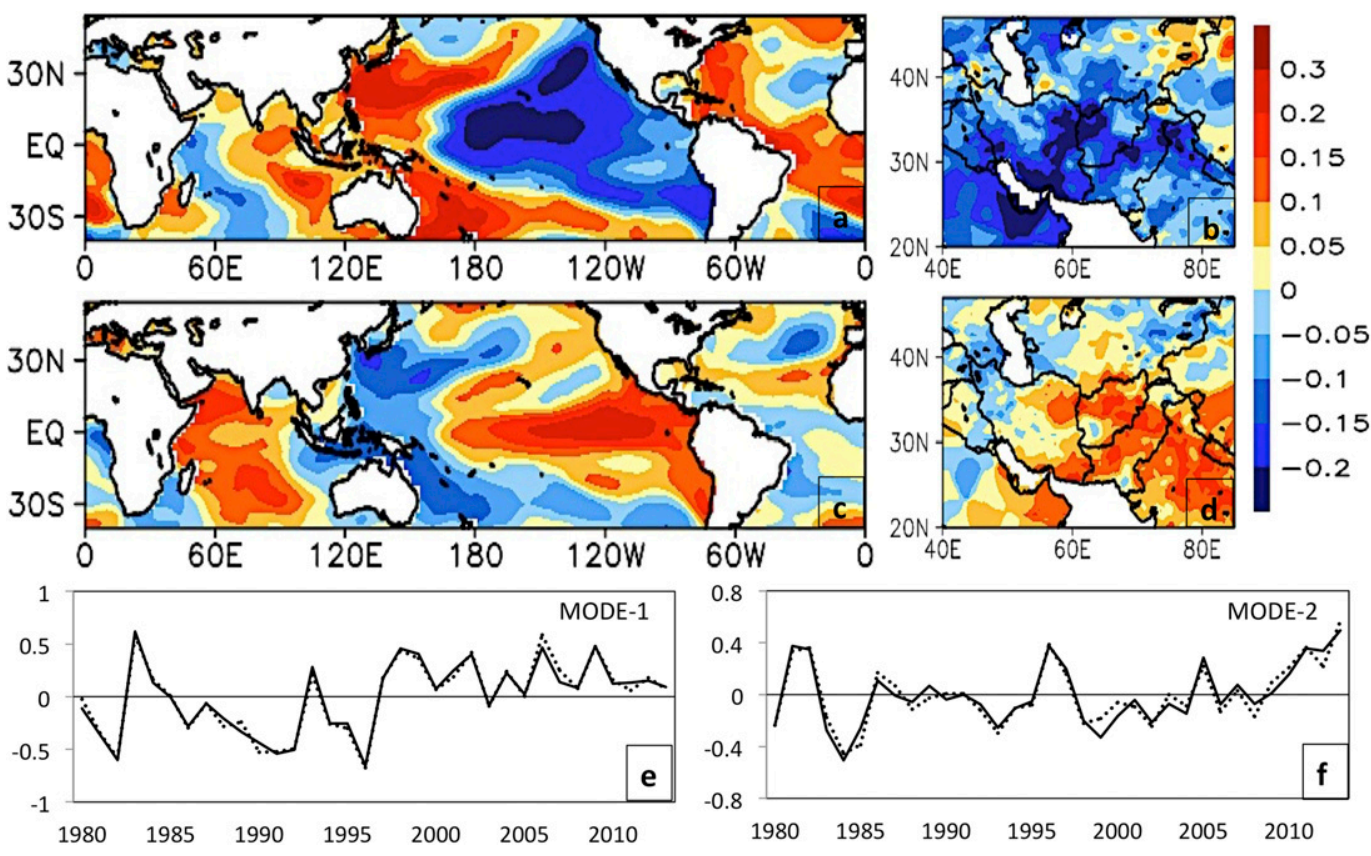

FIG. 6. As in Fig. 5, but for the period 1980/81-2014/15.

of the long-term changes in CSWA winter precipitation related to the SSTs in the heavily loaded regions.

The second CCA mode (Fig. 5c) explains $20 \%$ of the total domain variance and displays a warming of the global oceans over the period 1950/51-2014/15, with three distinct areas of significantly warm SST anomalies. Evidence suggests that the global oceans were significantly cooler than average prior to mid-1970s, followed by the abrupt warming of the Indian Ocean, the western Pacific, and the Atlantic in the following decades (Compo and Sardeshmukh 2010; Hoell and Funk 2014; McGregor et al. 2014; Hoell et al. 2017). The associated mode-2 canonical component time series (Fig. 5f) captures the above features with a slight cooling trend from 1950 to 1973 and a warming influence thereafter. The rapid rise post-1999 is probably associated with the prominent warming of the western Pacific and the Atlantic Ocean [see Fig. 5 in Hoell and Funk (2014)]. The mode- 2 predictand loading pattern (Fig. 5d) explains $16 \%$ of the total variance and is fairly similar to the west-east precipitation dipole structure displayed in Fig. $5 \mathrm{~b}$ for mode 1 . The similarity between the two modes indicates that the changes in CSWA winter precipitation are also related to the global SST trends.

As seen in Fig. 6a, the leading SST-predictor mode for the period 1980/81-2014/15 is dominated by an ENSOlike response with extensive negative SST loadings covering a wide region of the central and eastern Pacific accompanied by positive SST anomalies in the western Pacific sector. This mode explains $27 \%$ of the total domain variance. Notably, the strongest negative SST anomalies occur along a narrow band that extends southwestward off the North American coastline and in the equatorial central Pacific region that includes the Niño-3.4 domain $\left(5^{\circ} \mathrm{S}-5^{\circ} \mathrm{N}, 170^{\circ}-120^{\circ} \mathrm{W}\right)$. In this polarity, the SST loadings manifest features that have a resemblance to the cold phase of the Pacific decadal variability (Barlow et al. 2001) combined with the recent prevalence of central Pacific La Niña events relative to the eastern Pacific La Niña events (Lee and McPhaden 2010). This scenario also includes the NAO-like signature in the North Atlantic (Robertson et al. 2000) and a dipole with weak centers of opposite-signed SST anomalies over the tropical western and southeastern Indian Ocean, with some similarities to the Indian Ocean dipole (IOD) (Saji et al. 1999).

The leading predictand loading pattern of CSWA winter precipitation (Fig. 6b) accounts for $23 \%$ of the total variance and is characterized by a monopole pattern with large negative loadings over Iran, Afghanistan, Pakistan, and northeastern parts of Arabian Peninsula. The spatial features exhibit a close similarity to the precipitation deficit anomaly map associated with the recent extreme droughts over the CSWA region [see Fig. 1 in Barlow et al. (2016)]. It appears that the strong loadings are concentrated over regions that are most sensitive to the modifications in winter season precipitation amount influenced by the SST variations discussed above. Notably, the region with the largest same-sign loadings is the region with maximum winter-fraction 

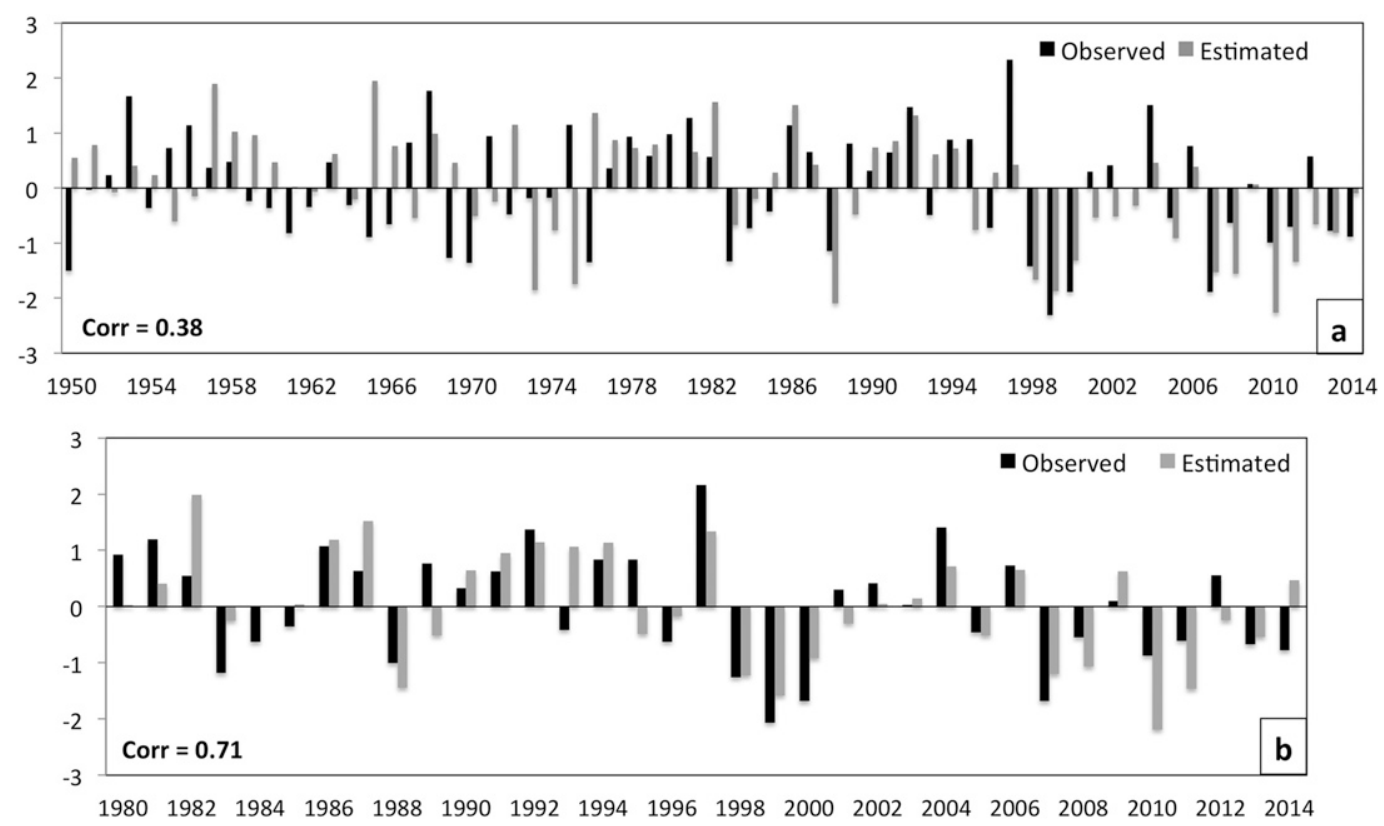

FIG. 7. Standardized wintertime (NDJFMA) precipitation time series of observation and forecasts over CSWA region for (a) 1950/51-2014/15 and (b) 1980/81-2014/15, using the leave-one-out approach.

precipitation (Fig. 2c). The canonical component time series (Fig. 6e) associated with this mode exhibit a very high correlation coefficient of 0.99 and contains both interannual and decadal variability, with an increased frequency of positive anomalies evident after the mid1990s. Mantua and Hare (2002) reported that from 1976/77 through at least the mid-1990s the PDO exhibited a warm (i.e., positive) phase, which is typically associated with enhanced frequency of El Niño events (Verdon and Franks 2006) and an increase in CSWA regional precipitation (Mariotti 2007; Rana et al. 2017). However, from 1999 onward a negative phase of PDO occurred, which was in line with the increased frequency of La Niña events and an increase in the occurrence of drought episodes over CSWA (Hoell and Funk 2014; Lyon et al. 2014).

The second CCA mode for the period 1980/81-2014/15 shown in Fig. 6c shows a zonal anomaly pattern of strong positive SST anomalies spanning the tropical equatorial Pacific extending from the west coast of South America to the western Pacific and northward along the west coast of North America. An anomaly of opposite sign covers the equatorial western tropical Pacific, extending northeast and southeast into the subtropics. This pattern accounts for $18 \%$ of the total domain variance and resembles the ENSO mode displayed in Kawamura (1994). Strong positive SST loadings are also observed over the tropical Indian Ocean that are possibly related to the strong ENSO-induced changes in the Walker circulation that result in positive SST anomalies across the entire Indian Ocean (Klein et al. 1999). The predictand loadings (Fig. 6d) depict an ENSO-related precipitation anomaly pattern with positive loadings over much of the CSWA region and account for $18 \%$ of the total domain variance. The corresponding canonical time series in Fig. $6 f$ contains some evidence of the ENSO-related fluctuations in CSWA winter precipitation with a mild upward trend since the late 1990s, likely associated with the increased frequency of central Pacific ENSO events and the recent decadal shift in the Pacific SST (Lyon et al. 2014; Hoell et al. 2014b).

\section{c. CCA cross-validated skill}

Cross-validation is conducted to evaluate the overall forecasting skill of the CCA model. The standardized year-to-year time series of observations and crossvalidated precipitation forecasts obtained for the periods 1950/51-2014/15 (Fig. 7a) and 1980/81-2014/15 (Fig. 7b) yields a domain average correlation skill of 0.38 and 0.71 , respectively. For the period 1950/51-2014/15 the time series in Fig. 7a depicts an improved level of agreement between the observed and the modelestimated precipitation time series after the mid-1970s. Prior to this period, the forecast skill is relatively low and less reliable, as a result of which the model 
produces a moderate correlation score of 0.38 for the overall experiment. A close comparison of results shows that the time period (1950-76) during which the CCA model displayed a lower predictive skill is concomitant with the period in which the influence of ENSO on CSWA winter precipitation was rather weak (Fig. 4) and that of NAO was relatively strong. This, however, is a limitation of the prediction approach adopted here, namely that in the absence of a robust historical predictor-predictand relationship or trend, the model fails to establish a reliable physical link and is unable to reproduce the predictor response correctly.

For the period 1980/81-2014/15 (Fig. 7b) the crossvalidated CCA-based forecasts indicate considerable predictive skill by capturing the interannual variations in CSWA winter precipitation for most years. The model performs impressively with a high and potentially usable predictive skill of 0.71; however, for some extreme (driest and wettest) years discrepancies are apparent between the model estimates and observation. For example, during 1995/96 the model failed to capture the observed precipitation pattern, whereas for 1980/81 and $1981 / 82$ the model was unable to capture the overall magnitude of the observed seasonal precipitation.

For 1995/96, which was a weak La Niña year, the model failed to capture the observed precipitation anomaly pattern because the low positive NAO index (September-October average index: 0.5) suddenly changed to a strong negative value $(-1.5)$ in the following winter months. Previous findings on CSWA have recognized that other than the direct influence of tropical Pacific SST forcing, the region is also connected to the Pacific through the Middle East and the Atlantic Ocean (Barlow and Tippett 2008; Hoell et al. 2013; further discussed in the following section). Therefore, it is possible that during 1995/96 the indirect ENSO response on CSWA precipitation was significantly dampened by the strong positive phase of the NAO, leading to an increased precipitation activity over the region. Furthermore, the years 1980/81 and 1981/82 for which the model was unable to capture the overall magnitude of the observation were dominated by strong negative EAWR phase. According to Yin et al. (2014) the negative (positive) phase of EAWR contributes in reducing (enhancing) precipitation activity over CSWA.

All of the above results indicate that the potential predictability of CSWA wintertime precipitation has a strong dependency on the ENSO phenomenon, and the strengthening (weakening) of this relationship yields forecasts of higher (lower) predictive skill. In particular for the period 1980/81-2014/15 the forecasts are more skillful for years classified as strong to very strong ENSO years, suggesting that the regional precipitation anomalies are largely decided by the phase of ENSO. However, there are indications that, depending on the relative strength of the concomitant regional or largescale teleconnections, regional precipitation anomalies can be modified either directly (during non-ENSO years) or by way of partly modulating the strength of the ENSO-induced precipitation forcing. A recent example of this is the 2013/14 regional drought of CSWA discussed in Barlow and Hoell (2015). In addition to the aforementioned factors, random atmospheric variability may also result in the circulation and precipitation modifications over the CSWA region.

For the period 1980/81-2014/15, the wintertime precipitation anomaly composite maps for the seven driest and wettest years from observations (Figs. 8a,c) and SST-predicted (Figs. 8b,d) precipitation estimates are displayed. In general, this result showcases the ability of the CCA model to effectively reproduce and predict the spatial distribution pattern of CSWA observed precipitation anomalies during extreme precipitation years. The model-estimated precipitation demonstrates useful prediction skill by capturing the characteristic features of the spatial anomaly pattern similar to the observations. In particular, the success of the CCA approach in predicting the recent drought conditions over CSWA (as seen in Figs. 7b and 8b) is highly encouraging, given that the region is water stressed and prone to frequent severe droughts (Barlow et al. 2016).

For further assessment, additional spatial skill scores-mean bias $\left(\mathrm{mm} \mathrm{day}^{-1}\right)$, RMSE $\left(\mathrm{mm} \mathrm{day}^{-1}\right)$, and temporal anomaly correlation-are computed for the period 1980/81-2014/15 and shown in Fig. 9. The important aspects that contribute substantially to the final skill of the model include the relatively low biases (Fig. 9a) and modest correlation coefficients (Fig. 9c) distributed over areas that receive a significant amount of winter season precipitation as seen in Fig. 2c. The RMSE values are high over the mountainous regions and closely resemble the region's seasonal climatology (Fig. 2b) and standard deviation pattern [see Fig. 1c in Tippett et al. (2003)]. Combining the above information, it appears that in our prediction model the random error dominates over the systematic bias that is likely related to the year-to-year variations in the winter season precipitation. Finally, we compare the accuracy skill of our CCA prediction scheme against the climatology and persistence benchmark models for the period 1980/81-2014/15. Here the climatology model assumes the long-term mean as the forecast at all times (i.e., zero anomaly); the persistence model uses last year's observation as this year's forecast and the accuracy skill score is computed using the Nash-Sutcliffe efficiency criteria (Krause et al. 2005). 


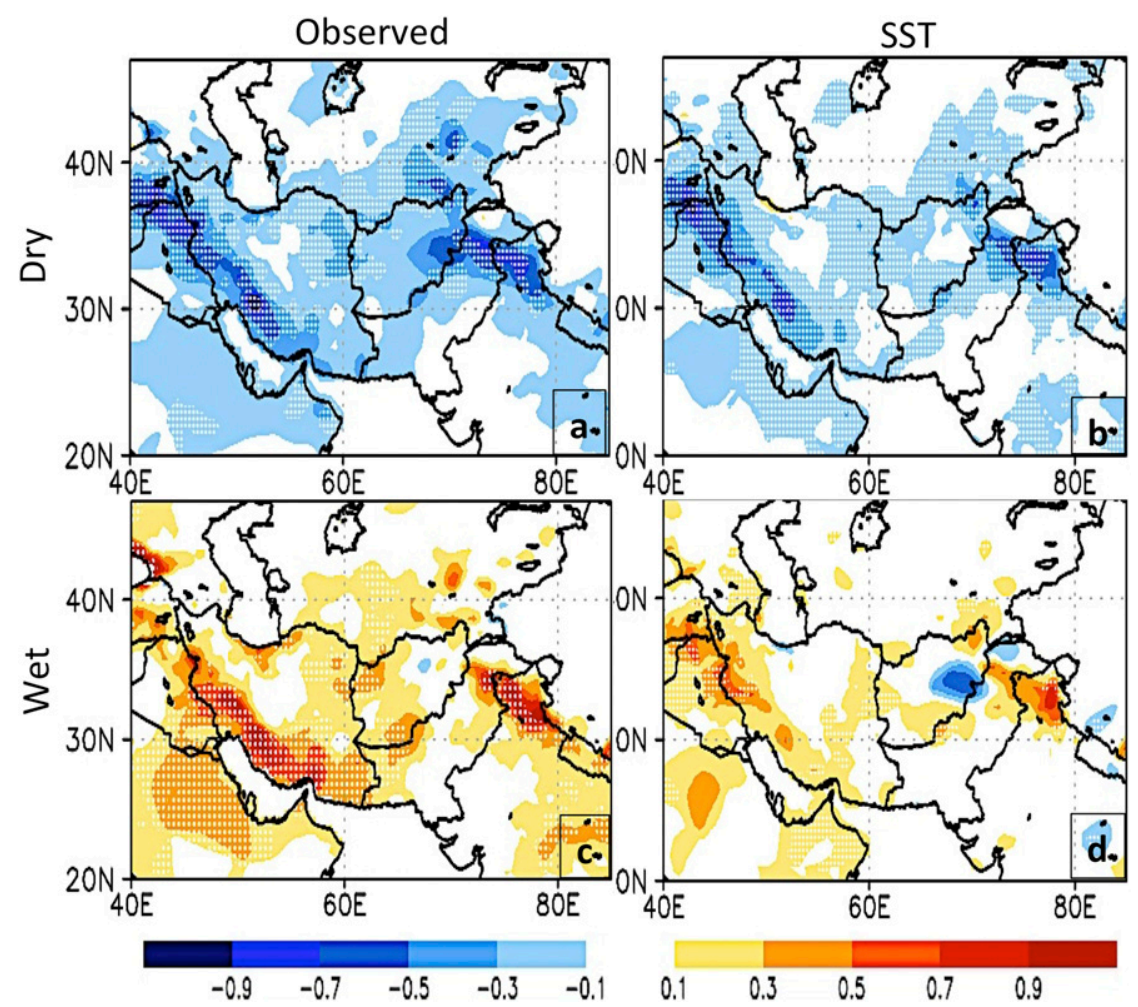

FIG. 8. The wintertime (NDJFMA) precipitation $\left(\mathrm{mm} \mathrm{day}^{-1}\right)$ anomaly composites for the seven driest and wettest years in the (a),(c) observed and (b),(d) SST-predicted precipitation for 1980/81-2014/15. White stippling indicates composite anomalies significant at 5\% level.

A negative skill score indicates that the CCA model is inferior to the reference model, whereas a $100 \%$ score signifies a perfect model. We find that the overall predictive skill of our model with respect to climatology and persistence is $47 \%$ and $58 \%$, respectively, which further confirms the success of the prediction approach adopted here.

\section{Large-scale SST forcing}

Figure 10 shows the composite anomaly maps of the preceding months' (September-October) SST variations corresponding to the seven driest (Fig. 10a) and wettest (Fig. 10b) winter precipitation years for the period 1980/81-2014/15. These results indicate that strong
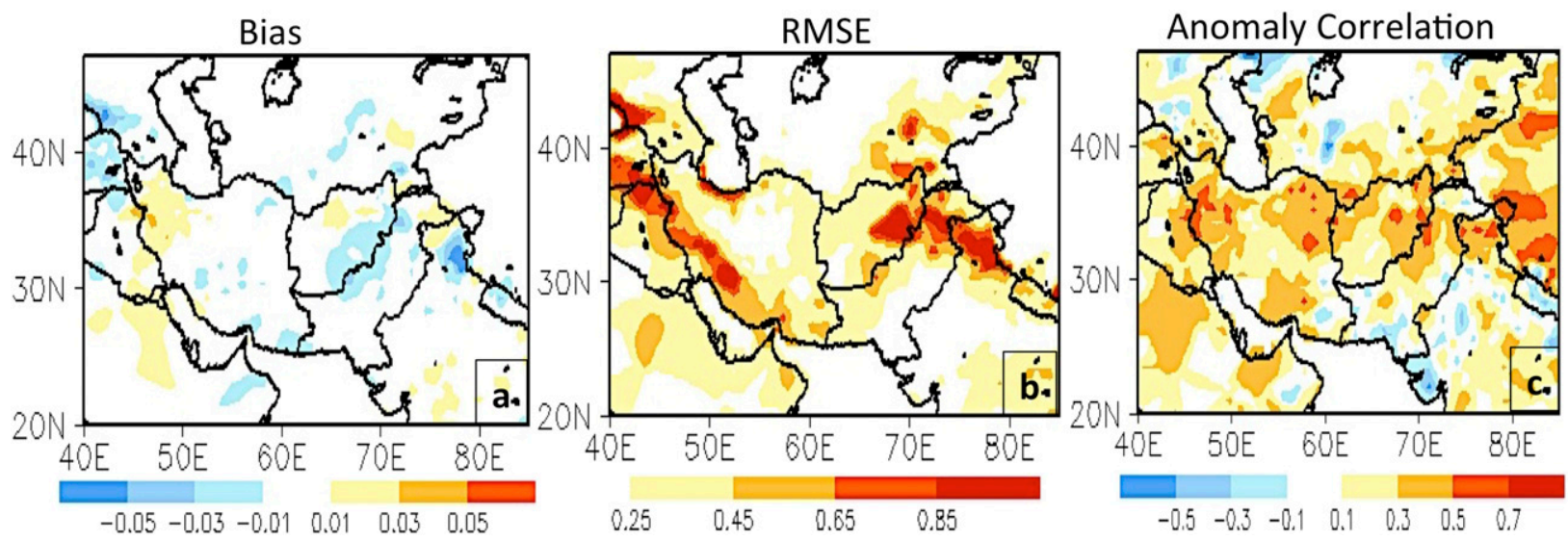

FIG. 9. The spatial maps for (a) bias, (b) RMSE, and (c) anomaly correlation between the observed and SST-predicted winter precipitation over CSWA for 1980/81-2014/15. 

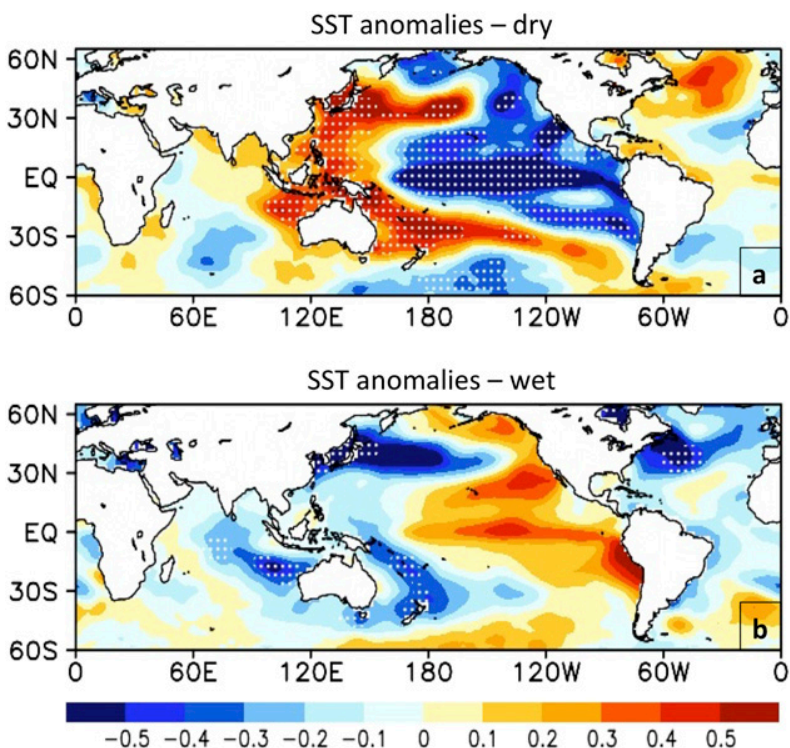

FIG. 10. Composite of SST $\left({ }^{\circ} \mathrm{C}\right)$ anomalies for the months preceding (September-October) the seven (a) driest and (b) wettest winter (NDJFMA) precipitation years for 1980/81-2014/15. White stippling indicates composite anomalies significant at $5 \%$ level.

and statistically significant variations in the Pacific sector (which include signatures of both ENSO and the PDO) lead to substantial precipitation modifications across the CSWA region. In the case of dry winter years the observed September-October SST expression along the equatorial belt shows strong similarities with the SST phase-3 La Niña pattern discussed in Johnson (2013), while the subtropical and extratropical signature resembles a developing cold phase of PDO similar to that in Hoell et al. (2015b).

Likewise, for the wet years the SST anomaly pattern in Fig. 10b appears to be a warm phase combination of ENSO and a PDO mode that tends to have a similar influence on CSWA precipitation anomalies. Although ENSO-related interannual and interdecadal variations have been recognized as the most important climate forcing of CSWA precipitation variability, positive (negative) NAO-like signals are visible in the North Atlantic for the extremely dry (wet) winter years.

To understand dynamical links to CSWA winter precipitation extremes, seasonal wind anomaly composites at 300, 500, and $850 \mathrm{hPa}$ are shown in Fig. 11 for the period 1980/81-2014/15. The precursory signals emerging in the September-October upper-level wind anomaly composites (not shown) for the driest (wettest) winter precipitation years depict strengthening (weakening) of the tropical Walker circulation accompanied by a northward (southward) shift of the westerly jet stream from its climatological position (i.e., from $25^{\circ}$ to $30^{\circ} \mathrm{N}$ in November-April). Niranjan Kumar and Ouarda (2014) showed that during El Niño years the uppertropospheric westerly jet stream shifts equatorward nearly $3^{\circ}-4^{\circ}$ of latitude over the Middle East and is responsible for above-normal precipitation over the region. These circulation features strengthen considerably during the following winter months (NDJFMA), with upper-level cyclonic (Fig. 11a) and anticyclonic (Fig. 11b) circulation anomalies straddling the equator, often discernible in the case of La Niña and El Niño events, respectively.

Previous studies have shown that anomalous diabatic heating in the tropical Pacific excites baroclinic (Barlow et al. 2002) and equivalent barotropic (Shaman and Tziperman 2005; Hoell et al. 2012, 2013) stationary Rossby waves that influence CSWA climate through modification of the regional circulation patterns. Shaman and Tziperman (2005) proposed a teleconnection mechanism that the wintertime ENSO conditions in the central Pacific produce stationary barotropic Rossby waves in the troposphere that propagate northeastward throughout the Northern Hemisphere over North America, the Atlantic, and the Middle East into western Asia, influencing the regional circulation (Barlow and Tippett 2008; Hoell et al. 2013). Recently, Niranjan Kumar et al. (2016) reported that during La Niña and El Niño events the wind anomalies over the Middle East region are easterlies and westerlies, respectively, in the upper and lower troposphere. Consistent with the above results, Fig. 11 indicates that for much the CSWA region the extratropical circulation response to the anomalous tropical Pacific SSTs (Fig. 10) consists of an anticyclonic (cyclonic) equivalent barotropic wave structure throughout the depth of the troposphere. Therefore during extreme dry (wet) winter years the reduced (enhanced) wintertime precipitation anomalies over the CSWA are typically associated with a strong northeasterly (southwesterly) wind flow from the Tibetan Plateau (Arabian Sea) responsible for advecting more (less) moisture into the region previously discussed in Hoell et al. (2012) and Mariotti (2007).

\section{Summary}

Central southwest Asia (CSWA), bounded by the domain $20^{\circ}-47^{\circ} \mathrm{N}, 40^{\circ}-85^{\circ} \mathrm{E}$, comprises a region that is water-stressed, societally vulnerable, and prone to large variations in precipitation during its primary precipitation season of November-April (NDJFMA). Evidence suggests that CSWA winter precipitation is strongly influenced by the Pacific sector SST forcing, much of which is attributed to the ENSO cycle-related 

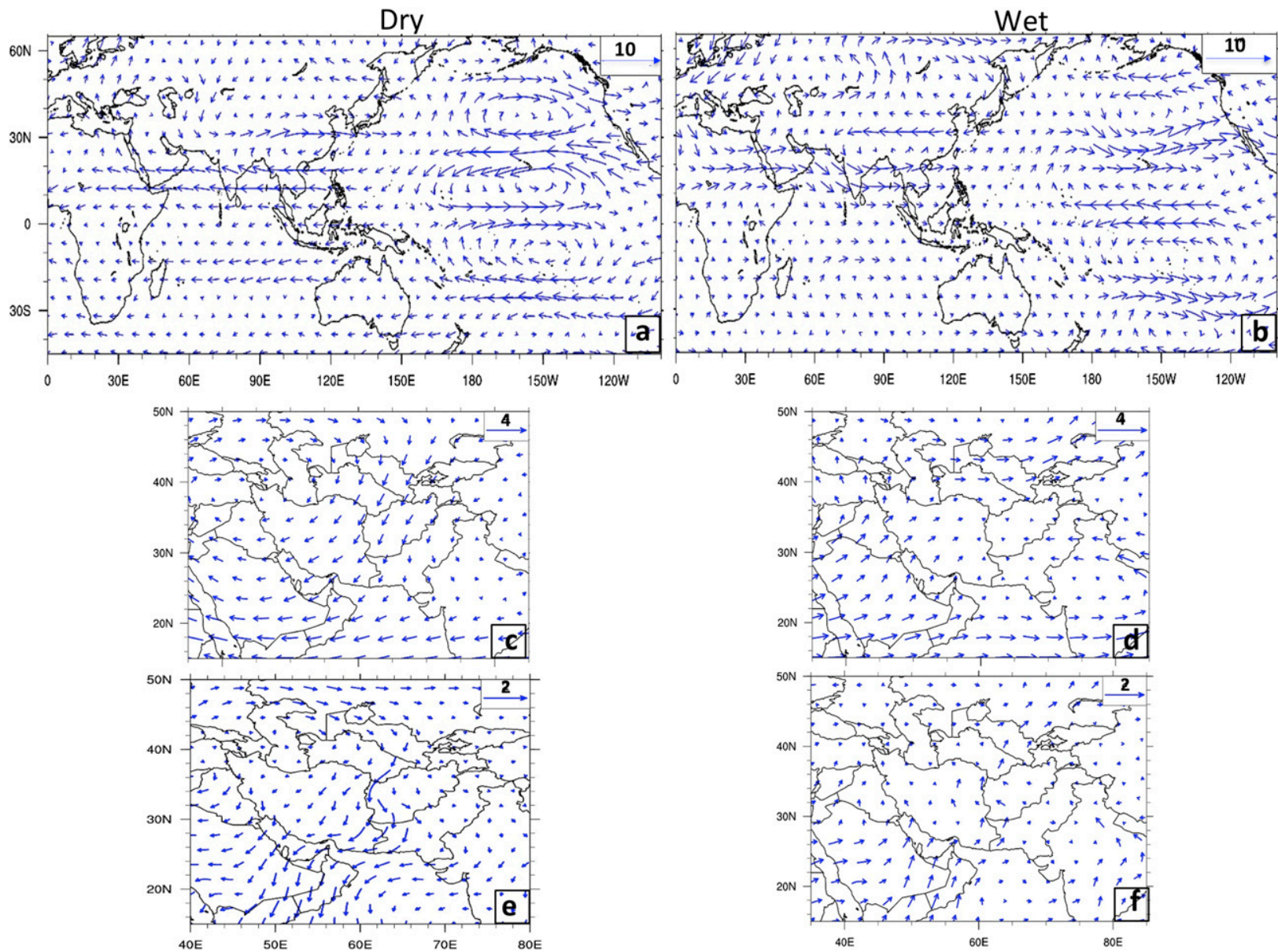

FIG. 11. Wintertime (NDJFMA) wind (vectors; $\mathrm{m} \mathrm{s}^{-1}$ ) anomaly composites for the seven driest and wettest precipitation years for 1980/81-2014/15 at (a),(b) 300, (c),(d) 500, and (e),(f) $850 \mathrm{hPa}$

interannual variability and the ENSO-like interdecadal variability (Hoerling and Kumar 2003; Barlow and Tippett 2008; Lyon et al. 2014; Barlow et al. 2016; Hoell et al. 2015b). To a large extent, these relationships are of significant value and have potential predictive capabilities for forecasting CSWA winter precipitation anomalies at various time scales (Barlow et al. 2002; Tippett et al. 2003; Barlow et al. 2005; Tippett et al. 2005; Hoell and Funk 2013).

In this study, we examined the predictability of CSWA wintertime precipitation anomalies for two sets of time periods 1950/51-2014/15 and 1980/81-2014/15 using the CCA approach. CCA is designed to find the most well-correlated patterns between a set of the predictors and predictands. The potential predictor patterns/modes of variability are identified using covariance analysis (Fig. 3) between the winter season (NDJFMA) precipitation and the preceding months' (September-October) SSTs. The lead-lag covariance pattern depicted SST expressions similar to ENSO and the NAO pattern, based on which quasi-global SST field $\left(40^{\circ} \mathrm{S}-55^{\circ} \mathrm{N}\right.$, all longitudes) was considered as the most optimal predictor domain for CCA diagnostics.

The leading predictor modes of the two CCA experiments (Figs. 5 and 6) revealed that for CSWA a substantial component of the predictive skill comes from the SST variability in the Pacific associated with both the interannual (ENSO) and the interdecadal (PDO) climate variations. The regional precipitation response to the large-scale Pacific forcing is such that the in-phase development of ENSO and PDO anomalies (El Niño and warm PDO or La Niña and cold PDO) tends to produce negative (positive) precipitation anomalies over CSWA in the following winter months (Fig. 10). The teleconnection mechanism linking the Pacific sector variability to CSWA precipitation modifications is through the interaction of the westerly jet stream with the upper-tropospheric Rossby wave train that shifts the westerly jet track north (south) of its mean position, resulting in anticyclonic (cyclonic) circulations over CSWA throughout the troposphere (Fig. 11). 
The cross-validated forecast skill of the two CCA experiments (Fig. 7) showed that on the interannual time scale skillful predictability of CSWA winter precipitation arises as a result of the influence of ENSO, and years with strongest ENSO conditions yield forecasts with more usable skill levels. The superior domain average correlation skill of 0.71 obtained for the 1980/812014/15 CCA experiment validates the above results. However, on longer time scales the influence of ENSO on CSWA winter precipitation varied in strength (Fig. 4), and the strengthening (weakening) of this relationship was strongly associated with the higher (lower) predictability of the regional precipitation as seen in the case of 1950/51-2014/15 cross-validated forecast skill.

Other than the ENSO-related sources, random atmospheric variability may also result in anomalous circulation and precipitation modifications over CSWA. On a positive note, the North Atlantic variability and the long-term SST trends have shown to provide weaker but useful regional predictive information on interannual and longer time scales. A close assessment of the cross-validated forecast skill has shown that nonENSO-related patterns, in particular the NAO, do not contribute materially to the seasonal predictive skill despite their important role in the regional precipitation variability (Fig. 3). There are indications that, depending on the relative strength of the concomitant regional or large-scale teleconnections, the regional precipitation anomalies tend to get modified either directly (during non-ENSO years) or by way of partly modulating the strength of the ENSO-induced forcing.

Overall the results presented in this study are highly encouraging. The regional forecasts for the 1980/812014/15 period indicate considerable predictive skill and can potentially contribute to early planning and preparedness. Further improvements in the model performance can focus on the inclusion of regional predictors that contribute quantitatively to the predictive skill of the model.

Acknowledgments. The authors would like to extend their sincere thanks to the Victoria University of Wellington (VUW), New Zealand for supporting this research. The authors also thank Dr. Mathew Barlow, Dr. Andrew Hoell, and the anonymous reviewer for their valuable comments that helped to improve this manuscript substantially. The lead author acknowledges VUW for the Doctoral Scholarship Award.

\section{REFERENCES}

Agrawala, S., M. Barlow, H. Cullen, and B. Lyon, 2001: The drought and humanitarian crisis in Central and Southwest
Asia: A climate perspective. IRI Special Rep. 01-11, International Research Institute for Climate and Society, $24 \mathrm{pp}$.

Aizen, E. M., V. B. Aizen, J. M. Melack, T. Nakamura, and T. Ohta, 2001: Precipitation and atmospheric circulation patterns at mid-latitudes of Asia. Int. J. Climatol., 21, 535-556, https://doi.org/10.1002/joc.626.

Barlow, M., and M. K. Tippett, 2008: Variability and predictability of central Asia river flows: Antecedent winter precipitation and large-scale teleconnections. J. Hydrometeor., 9, 13341349, https://doi.org/10.1175/2008JHM976.1.

, and A. Hoell, 2015: Drought in the Middle East and centralsouthwest Asia during winter 2013/14 [in "Explaining Extreme Events of 2014 from a Climate Perspective"]. Bull. Amer. Meteor. Soc., 96 (12), S71-S76, https://doi.org/10.1175/ BAMS-D-15-00127.1.

_- S. Nigam, and E. H. Berbery, 2001: ENSO, Pacific decadal variability, and U.S. summertime precipitation, drought, and streamflow. J. Climate, 14, 21052128, https://doi.org/10.1175/1520-0442(2001)014<2105: EPDVAU $>2.0 . \mathrm{CO} ; 2$.

- H. Cullen, and B. Lyon, 2002: Drought in central and southwest Asia: La Niña, the warm pool, and Indian Ocean precipitation. J. Climate, 15, 697-700, https://doi.org/10.1175/ 1520-0442(2002)015<0697:DICASA > 2.0.CO;2.

, M. Wheeler, B. Lyon, and H. Cullen, 2005: Modulation of daily precipitation over southwest Asia by the Madden-Julian oscillation. Mon. Wea. Rev., 133, 3579-3594, https://doi.org/ 10.1175/MWR3026.1.

—, B. Zaitchik, S. Paz, E. Black, J. Evans, and A. Hoell, 2016: A review of drought in the Middle East and Southwest Asia. J. Climate, 29, 8547-8574, https://doi.org/10.1175/JCLI-D13-00692.1.

Barnett, T. P., and R. Preisendorfer, 1987: Origins and levels of monthly and seasonal forecast skill for United States surface air temperatures determined by canonical correlation analysis. Mon. Wea. Rev., 115, 1825-1850, https://doi.org/10.1175/ 1520-0493(1987)115<1825:OALOMA > 2.0.CO;2.

Barnston, A. G., and C. F. Ropelewski, 1992: Prediction of ENSO episodes using canonical correlation analysis. J. Climate, 5, 1316-1345, https://doi.org/10.1175/1520-0442(1992)005<1316: POEEUC $>2.0 . \mathrm{CO} ; 2$.

, and T. M. Smith, 1996: Specification and prediction of global surface temperature and precipitation from global SST using CCA. J. Climate, 9, 2660-2697, https://doi.org/ 10.1175/1520-0442(1996)009<2660:SAPOGS > 2.0.CO;2.

_ W. Whiao, and V. Kumar, 1996: Long-lead forecasts of seasonal precipitation in Africa using CCA. Wea. Forecasting, 11, 506-520, https://doi.org/10.1175/1520-0434(1996)011<0506: LLFOSP $>2.0 . \mathrm{CO} ; 2$.

Bretherton, C. S., C. Smith, and J. M. Wallace, 1992: An intercomparison of methods for finding coupled patterns in climate data. J. Climate, 5, 541-560, https://doi.org/10.1175/ 1520-0442(1992)005<0541:AIOMFF>2.0.CO;2.

Cassou, C., C. Deser, L. Terray, J. W. Hurrell, and M. Drévillon, 2004: Summer sea surface temperature conditions in the North Atlantic and their impact upon the atmospheric circulation in early winter. J. Climate, 17, 3349-3363, https://doi.org/10.1175/ 1520-0442(2004)017<3349:SSSTCI >2.0.CO;2.

Compo, G. P., and P. D. Sardeshmukh, 2010: Removing ENSOrelated variations from the climate record. J. Climate, 23, 1957-1978, https://doi.org/10.1175/2009JCLI2735.1.

Cullen, H. M., and P. B. deMenocal, 2000: North Atlantic influence on Tigris-Euphrates streamflow. Int. J. Climatol., 20, 
853-863, https://doi.org/10.1002/1097-0088(20000630)20: $8<853:$ :AID-JOC497>3.0.CO;2-M.

_ A. Kaplan, P. A. Arkin, and P. B. deMenocal, 2002: Impact of the North Atlantic Oscillation on Middle Eastern climate and streamflow. Climatic Change, 55, 315-338, https://doi.org/ 10.1023/A:1020518305517.

Czaja, A., and C. Frankignoul, 2002: Observed impact of Atlantic SST anomalies on the North Atlantic Oscillation. J. Climate, 15, 606-623, https://doi.org/10.1175/1520-0442(2002)015<0606: OIOASA $>2.0 . \mathrm{CO} ; 2$.

Dee, D. P., and Coauthors, 2011: The ERA-Interim reanalysis: Configuration and performance of the data assimilation system. Quart. J. Roy. Meteor. Soc., 137, 553-597, https://doi.org/10.1002/qj.828.

Deser, C., M. A. Alexander, S.-P. Xie, and A. S. Philips, 2010: Sea surface temperature variability: Patterns and mechanism. Annu. Rev. Mar. Sci., 2, 115-143, https://doi.org/10.1146/ annurev-marine-120408-151453.

Filippi, L., E. Palazzi, J. von Hardenberg, and A. Provenzale, 2014: Multidecadal variations in the relationship between the NAO and winter precipitation in the Hindu-Kush Karakoram. J. Climate, 27, 7890-7902, https://doi.org/10.1175/JCLI-D-14-00286.1.

Gall, C., 2008: War and drought threaten Afghan food supply. New York Times, 19 September 2008, NY ed., p. A1, http://www. nytimes.com/2008/09/19/world/asia/19afghan.html.

Goddard, L., S. J. Mason, S. E. Zebiak, R. C. Ropelewski, B. Basher, and M. A. Cane, 2001: Current approaches to seasonal-to-interannual climate predictions. J. Climatol., 21, 1111-1152, https://doi.org/10.1002/joc.636.

Graham, N. E., J. Michaelsen, and T. P. Barnett, 1987: Investigations of the El Niño Southern Oscillation with statistical models: 1. Predictor field characteristics. J. Geophys. Res., 92, 14 251-14 270, https://doi.org/10.1029/JC092iC13p14251.

Harris, I., P. D. Jones, T. J. Osborn, and D. H. Lister, 2014: Updated high-resolution grids of monthly climatic observationsThe CRU TS3.10 dataset. Int. J. Climatol., 34, 623-642, https:// doi.org/10.1002/joc.3711.

Hoell, A., and C. Funk, 2013: The ENSO-related west Pacific sea surface temperature gradient. J. Climate, 26, 9545-9562, https://doi.org/10.1175/JCLI-D-12-00344.1.

- and — 2014: Indo-Pacific sea surface temperature influences on failed consecutive rainy seasons over eastern Africa. Climate Dyn., 43, 1645-1660, https://doi.org/10.1007/ s00382-013-1991-6.

_ M. Barlow, and R. Saini, 2012: The leading pattern of intraseasonal and interannual Indian Ocean precipitation variability and its relationship with Asian circulation during the boreal cold season. J. Climate, 25, 7509-7526, https://doi.org/ 10.1175/JCLI-D-11-00572.1.

,-- , and — 2013: Intraseasonal and seasonal-tointerannual Indian Ocean convection and hemispheric teleconnections. J. Climate, 26, 8850-8867, https://doi.org/10.1175/ JCLI-D-12-00306.1.

C. Funk, and M. Barlow, 2014a: The regional forcing of Northern hemisphere drought during recent warm tropical west Pacific Ocean La Niña events. Climate Dyn., 42, 32893311, https://doi.org/10.1007/s00382-013-1799-4.

- — - and — 2014b: La Niña diversity and northwest Indian Ocean Rim teleconnections. Climate Dyn., 43, 27072724, https://doi.org/10.1007/s00382-014-2083-y.

, S. Shukla, M. Barlow, F. Cannon, C. Kelley, and C. Funk, 2015a: The forcing of monthly precipitation variability over Southwest Asia during the boreal cold season. J. Climate, 28, 7038-7056, https://doi.org/10.1175/JCLI-D-14-00757.1.
_ C. Funk, and M. Barlow, 2015b: The forcing of southwestern Asia teleconnections by low-frequency sea surface temperature variability during boreal winter. J. Climate, 28, 1511-1526, https://doi.org/10.1175/JCLI-D-14-00344.1.

— M. Barlow, F. Cannon, and T. Xu, 2017: Oceanic origins of historical Southwest Asia precipitation during the boreal cold season. J. Climate, 30, 2885-2903, https://doi.org/10.1175/ JCLI-D-16-0519.1.

Hoerling, M., and A. Kumar, 2003: The perfect ocean for drought. Science, 299, 691-694, https://doi.org/10.1126/science.1079053.

Huang, B., and Coauthors, 2017: Extended Reconstructed Sea Surface Temperature, version 5 (ERSSTv5): Upgrades, validations, and intercomparisons. J. Climate, 30, 8179-8205, https://doi.org/10.1175/JCLI-D-16-0836.1.

Johnson, N. C., 2013: How many ENSO flavors can we distinguish? J. Climate, 26, 4816-4827, https://doi.org/10.1175/ JCLI-D-12-00649.1.

Kar, S. C., and S. Rana, 2014: Interannual variability of winter precipitation over northwest India and adjoining region: Impact of global forcings. Theor. Appl. Climatol., 116, 609-623, https://doi.org/10.1007/s00704-013-0968-z.

Kawamura, R., 1994: A rotated EOF analysis of global sea surface temperature variability with interannual and interdecadal scales. J. Phys. Oceanogr., 24, 707-715, https://doi.org/10.1175/ 1520-0485(1994)024<0707:AREAOG > 2.0.CO;2.

Klein, S. A., B. J. Soden, and N.-C. Lau, 1999: Remote sea surface variations during ENSO: Evidence for a tropical atmospheric bridge. J. Climate, 12, 917-932, https://doi.org/10.1175/ 1520-0442(1999)012<0917:RSSTVD>2.0.CO;2.

Krause, P., D. P. Boyle, and F. Bäse, 2005: Comparison of different efficiency criteria for hydrologic model assessment. Adv. Geosci., 5, 89-97, https://doi.org/10.5194/adgeo-5-89-2005.

Krichak, S. O., J. S. Breitgand, S. Gualdi, and S. B. Feldstein, 2014: Teleconnection-extreme precipitation relationships over the Mediterranean region. Theor. Appl. Climatol., 117, 679-692, https://doi.org/10.1007/s00704-013-1036-4.

Lau, K. M., and J. S. Boyle, 1987: Tropical and extratropical forcing of the large-scale circulation: A diagnostic study. Mon. Wea. Rev., 115, 400-428, https://doi.org/10.1175/1520-0493(1987)115<0400: TAEFOT $>2.0 . \mathrm{CO} ; 2$.

Lee, T., and M. J. McPhaden, 2010: Increasing intensity of El Niño in the central-equatorial Pacific. Geophys. Res. Lett., 37, L14603, https://doi.org/10.1029/2010GL044007.

Liebmann, B., 1987: Observed relationships between largescale tropical convection and the tropical circulation on subseasonal time scales during Northern Hemisphere winter. J. Atmos. Sci., 44, 2543-2561, https://doi.org/10.1175/ 1520-0469(1987)044<2543:ORBLST>2.0.CO;2.

Lyon, B., A. Barnston, and D. DeWitt, 2014: Tropical Pacific forcing of a 1998-1999 climate shift: Observational analysis and climate model results for the boreal spring season. Climate Dyn., 43, 893-909, https://doi.org/10.1007/s00382-013-1891-9.

Mantua, N. J., and S. R. Hare, 2002: The Pacific decadal oscillation. J. Oceanogr., 58, 35-44, https://doi.org/10.1023/A:1015820616384.

Mariotti, A., 2007: How ENSO impacts precipitation in southwest central Asia. Geophys. Res. Lett., 34, L16706, https://doi.org/ 10.1029/2007GL030078.

Martyn, D., 1992: Climates of the World. Elsevier, 436 pp.

Marzban, C., S. Sandgathe, and J. D. Doyle, 2014: Model tuning with canonical correlation analysis. Mon. Wea. Rev., 142, 2018-2027, https://doi.org/10.1175/MWR-D-13-00245.1.

McGregor, S., A. Timmermann, M. F. Stuecker, M. H. England, M. Merrifield, F. F. Jin, and Y. Chikamoto, 2014: Recent 
Walker circulation strengthening and Pacific cooling amplified by Atlantic warming. Nat. Climate Change, 4, 888-892, https:// doi.org/10.1038/nclimate2330.

Newman, M., and Coauthors, 2016: The Pacific decadal oscillation, revisited. J. Climate, 29, 4399-4427, https://doi.org/10.1175/ JCLI-D-15-0508.1.

Niranjan Kumar, K., and T. B. M. J. Ouarda, 2014: Precipitation variability over UAE and global SST teleconnections J. Geophys. Res. Atmos., 119, 10313-10322, https://doi.org/ 10.1002/2014JD021724.

, S. Sandeep, and R. S. Ajayamohan, 2016: Wintertime precipitation variability over the Niranjan Arabian Peninsula and its relationship with ENSO in the CAM4 simulations. Climate Dyn., 47, 2443-2454, https://doi.org/10.1007/ s00382-016-2973-2.

Rana, S., J. McGregor, and J. Renwick, 2015: Precipitation seasonality over the Indian subcontinent: An evaluation of gauge, reanalyses, and satellite retrievals. J. Hydrometeor., 16, 631651, https://doi.org/10.1175/JHM-D-14-0106.1.

,-- , and -2017 : Wintertime precipitation climatology and ENSO sensitivity over central southwest Asia. Int. J. Climatol., 37, 1494-1509, https://doi.org/10.1002/joc.4793.

Recalde-Coronel, G. C., A. G. Barnston, and A. G. Muñoz, 2014: Predictability of December-April rainfall in coastal and Andean Ecuador. J. Appl. Meteor. Climatol., 53, 1471-1493, https://doi.org/10.1175/JAMC-D-13-0133.1.

Robertson, A. W., C. R. Mechoso, and Y.-J. Kim, 2000: The influence of Atlantic sea surface temperature anomalies on the North Atlantic Oscillation. J. Climate, 13, 122-138, https:// doi.org/10.1175/1520-0442(2000)013<0122:TIOASS > 2.0.CO;2.

Saji, N. H., B. N. Goswami, P. N. Vinayachandran, and T. Yamagata, 1999: A dipole in the tropical Indian Ocean. Nature, 401, 360-363, https://doi.org/10.1038/43854.

Schneider, U., A. Becker, P. Finger, A. Meyer-Christoffer, M. Ziese, and B. Rudolf, 2014: GPCC's new land surface precipitation climatology based on quality-controlled in situ data and its role in quantifying the global water cycle. Theor. Appl. Climatol., 115, 15-40, https://doi.org/10.1007/s00704-013-0860-x.

Shabbar, A., B. R. Bonsal, and K. Szeto, 2011: Atmospheric and oceanic variability associated with growing season droughts and pluvials on the Canadian Prairies. Atmos.-Ocean, 49, 339355, https://doi.org/10.1080/07055900.2011.564908.
Shaman, J., and E. Tziperman, 2005: The effect of ENSO on Tibetan Plateau snow depth: A stationary wave teleconnection mechanism and implications for the South Asian monsoons. J. Climate, 18, 2067-2079, https://doi.org/10.1175/JCLI3391.1.

Smith, T. M., and R. W. Reynolds, 2003: Extended reconstruction of global sea surface temperatures based on COADS data (1854-1997). J. Climate, 16, 1495-1510, https://doi.org/10.1175/ 1520-0442-16.10.1495.

Tippett, M. K., Barlow, M. and B. Lyon, 2003: Statistical correction of central southwest Asia winter precipitation simulations. Int. J. Climatol., 23, 1421-1433, https://doi.org/10.1002/joc.947.

—, Goddard, L. and A. G. Barnston, 2005: Statistical-dynamical seasonal forecasts of central-southwest Asian winter precipitation. J. Climate, 18, 1831-1843, https://doi.org/10.1175/ JCLI3371.1.

, T. DelSole, S. J. Mason, and A. G. Barnston, 2008: Regressionbased methods for finding coupled patterns. J. Climate, 21, 4384-4398, https://doi.org/10.1175/2008JCLI2150.1.

Trigo, R. M., C. Gouveia, and D. Barriopedro, 2010: The intense 2007-2009 drought in the Fertile Crescent: Impacts and associated atmospheric circulation. Agric. For. Meteor., 150, 12451257, https://doi.org/10.1016/j.agrformet.2010.05.006.

Verdon, D. C., and S. W. Franks, 2006: Long-term behaviour of ENSO: Interactions with the PDO over the past 400 years inferred from paleoclimate records. Geophys. Res. Lett., 33, L06712, https://doi.org/10.1029/2005GL025052.

Wilks, D. S., 1995: Statistical Methods in the Atmospheric Sciences. Academic Press, 467 pp.

Yin, Z.-Y., H. Wang, and X. Liu, 2014: A comparative study on precipitation climatology and interannual variability in the lower midlatitude East Asia and central Asia. J. Climate, 27, 7830-7848, https://doi.org/10.1175/ JCLI-D-14-00052.1.

Yu, Z.-P., P.-S. Chu, and T. Schroeder, 1997: Predictive skills of seasonal to annual rainfall variations in the U.S. affiliated Pacific islands: Canonical correlation analysis and multivariate principal component regression approaches. J. Climate, 10, 2586-2599, https://doi.org/10.1175/1520-0442(1997)010<2586: PSOSTA $>2.0 . \mathrm{CO} ; 2$.

Zhang, Y., J. M. Wallace, and D. S. Battisti, 1997: ENSO-like interdecadal variability: 1900-93. J. Climate, 10, 1004-1020, https:// doi.org/10.1175/1520-0442(1997)010<1004:ELIV>2.0.CO;2. 